\section{Preparation for MRCP Part II}

By Paul Siklos and Stephen Olczak. Pp. viii +186 , illustrated. MTP Press in association with Update Publications, Boston, The Hague, Dordrecht, Lancaster, 1983. £9.95.

Heeding the motto 'Forewarned is forearmed' very few candidates are so naive as to take the MRCP 'on spec'. Most seek help, and quite an industry has developed to cater for their needs. Readers of Hospital Update will be familiar with the articles on Preparation for the MRCP by Paul Siklos and Stephen Olczak and those sections relating to the written part of the MRCP Part II form the basis of the book under review. Case histories, laboratory data and slides similar in standard and form to the actual examination are presented as well as answers and detailed commentaries on the questions. The material chosen is wide ranging and I was grateful that answers were supplied! While the examiners are always adding new material to the question bank, the contents of the book should provide good practice for the real thing, stimulate the reader to look up points of interest and reveal gaps in his knowledge.

J. G. LEWIS

Edgware General Hospital,

Edgware,

Middlesex.

\section{Progress in Obstetrics and Gynaecology. Vol. 3}

Edited by JoHN STUDD. Pp. 353, illustrated. Churchill Livingstone, Edinburgh, London, Melbourne, New York, 1983. £15.00.

Mr John Studd is to be congratulated on producing on time Volume 3 of what has become an annual publication, and the most interesting 'up date' in Obstetrics and Gynaecology in the English language. The present volume-divided into three sections: obstetrics, oncology and gynaecology-consists of 26 chapters, written singly or jointly by 33 authors, of whom 14 are from outside the U.K.

As usual in this type of publication, authors writing on a circumscribed subject are given the easier task and produce the most satisfying results, such as Sir John Dewhurst's chapter on botyroid sarcoma, Dr Begent's on germ cell tumours of the ovary, and John Kelly's on vesico-vaginal fistulae. Preference for specific chapters must refiect the reader's interests as much as the author's expertise; there are chapters on placental proteins, the traditional subjects of induction of, and uterine action in, labour, trophoblastic disease, various aspects of infertility, and IUDs. Of the more wide ranging reviews, this reader particularly enjoyed the chapters on ectopic pregnancy, chlamydial infection, genetic amniocentesis, and obstetric problems in the black community. The sections on breast feeding and birth control and the post-hysterectomy syndrome are thoughtprovoking and all gynaecologists will benefit from Neuberger and Williams' section on liver disease and Professor Charles Douglas' attempt to disentangle the vulvar dystrophies. All chapters are short enough to maintain the reader's attention, are up to date, and have extensive references.

This series is highly recommended to all interested in new developments and current thinking in obstetrics and gynaecology: for MRCOG candidates (as well as their teachers and examiners) it is fast becoming essential reading.

H. E. ReISS

35 Devonshire Place, London WIN IPE.

\section{Clinical Biochemistry of Steroid Hormones: Methods and Applica- tions}

By J. K. Grant and G. H. Beastall. Pp. 303, illustrated. Croom Helm, London and Canberra, 1983. $£ 19.95$.

This book is intended for use as a handbook in laboratories concerned with the assays of steroids. The first chapter presents basic facts of steroid chemistry and biochemistry with almost a minimum of detail. Some of the information seems to have been added hastily and to be out of logical sequence. Chapter 2 considers the choice of biological fluids, the methods available for steroid analysis and introduces the concept of assay reliability. Steroid saturation analysis (Chapter 3 ) is dealt with more thoroughly than other aspects of the book as befits the importance of the technique to endocrine investigation. The authors accept the value of methods which complement this approach but give little detailed information. The regulation of steroid production is not included in Chapter 1 but dealt with in Chapters 4 to 6 which separately consider adrenocortical steroids, androgens and oestrogens with progesterone. The clinical value of selected steroid measurements are variably covered. The extent of coverage reflecting the experience of the authors. In the absence of data from the Glasgow laboratory a number of useful tables have been assembled with concentrations of steroids found in health and disease. These provide a good source of data for easy reference. The book concludes with 15 appendices, most of which are concerned with the details of methods most commonly used in the authors laboratory. These include the use of oestrogen/creatinine ratio for assessment of fetal well being and for assessment of ovarian response to gonadotrophins. The concept of these measurements has not been universally accepted. Some of the other methods described in detail are in practice rarely used. Much further reading is required if the objective of this book is to be achieved. The selected bibliography of each chapter is, however, sensible with the exception of numerous abstracts of papers read at scientific meetings and articles from trade journals. Overall, the book attempts to engender a better understanding of laboratory practice. The emphasis will not sustain the interests of clinicians.

J. W. HoNOUR,

Middlesex Hospital Medical School London WIP 7PN

Non-invasive Methods in Atherosclerosis Research. Atherosclerosis Reviews Volume 10

Edited by Ruth Johnsson Hegyel. Pp. xiv +200 , illustrated. Raven Press, New York, 1983. \$49.00.

Progress in the treatment of atherosclerosis in man has long been hampered by the lack of good non-invasive techniques demonstrating the presence of atheroma in specific vessels. Until such techniques are available, rates of progression or regression of lesions cannot be assessed making the assessment of therapeutic interventions much more difficult. Those methods that rely on the development of clinical events such as myocardial infarction in a group of individuals studied prospectively and treated for example with modification of diet, inevitably require very large numbers because of the insensitivity of the technique and the inadequate relationship between the end point and the development of atheroma itself.

This book attempts to provide an update on progress in the field of non-invasive investigation but makes depressing reading for a number of reasons.

Firstly although entitled Noninvasive Methods in Atherosclerosis Research, the book is actually a report of a symposium held in the United States in 1981 on non-invasive diagnosis in cardiovascular disease. Unfortunately the editor has perhaps not grasped the fact that much cardiovascular disease is not due to atherosclerosis and therefore some of the contributions to this symposium have no relevance at all to the title of this book. As is so often the case in reports of proceedings of a symposium held sometime before, time may take its toll of some contributions by the time publication occurs and the individual chapters vary considerably in quality. Secondly the message which comes across all too clearly is that little progress has been made in relation to the enormous amount of effort and money invested. It is perhaps sad that none of the contributors could bring themselves to acknowledge this but the gloss which is put on to most of the methods described cannot hide the underlying truth. This aspect is perhaps best summed up by the presence of only one illustration in the chapter on nuclear magnetic resonance imaging in cardiovascular diagnosis. This shows an illustration not of the heart but of a proton distribution map of a green pepper! 